\title{
On the Application of Common Reading Skills in Listening
}

\author{
Qiong Li \\ School of Foreign Languages \\ China West Normal University \\ Nanchong, Sichuan, China 637002 \\ E-mail: 1599844418@qq.com
}

\begin{abstract}
Listening and Reading are two receptive skills involving learners' language knowledge, background information, strategies, and skills. Generally speaking, second language learners do better in reading than in listening, and have a good command of reading skills. This paper presents how some readers' familiar reading skills can be applied in listening to help to improve their listening efficiently.
\end{abstract} ability

Keywords-strategies and skills; reading skills; listening

\section{INTRODUCTION}

Listening is one of the two main means of language input, the prerequisite of language learning and communication. A good command of listening will help people greatly in their daily communications, lessening the chances of misunderstanding. However, most college students in the west of China find listening the most difficult among four skills of English learning. A survey of the college English ability shows that students score the lowest in listening among the four skills of English, listening, speaking, reading and writing[1]. It is not easy to become a skilled and efficient listener, especially for some college students who don't have a good command of necessary English knowledge for listening. Listening depends on not only the listener's knowledge of the language code, and his knowledge of grammar, or his discourse processing strategies, but also his prior experience, or his background knowledge. In the past three decades, lots of work has been done to probe into the effect of strategy, especially learning strategy on language learning, including listening. It has been proved that strategies do facilitate listening. In fact, in addition to strategies, we also need a good command of listening skills, which will not only make listening easier, but also help improve listening comprehension to a certain extent. This paper presents how some readers' familiar reading skills can be used to help to improve their listening efficiently.

\section{STRATEGIES AND SKILLS}

Strategy refers to the specific way that we employ to solve a given problem[2]. Generally, there are three types of strategy: communication strategy, social strategy and learning strategy in language learning. The first two relate to output, how we productively express ourselves, how we deliver message to others. While learning strategy relates to input, how to taking in message from others by processing, storage and retrieval. Rubin (1975) uses learning strategies to mean 'the techniques or devices which a learner may use to acquire knowledge' [3]. O'Malley and Chamot define it as the special thought or behaviors that individuals use to help them comprehend, learn, or retain new information [4]. Typically, learning strategies are divided into three main categories: metacognitive strategies, cognitive strategies, and socioaffective strategies.

Metacognitive strategies involve planning for learning, thinking about the learning process as it is taking place, monitoring of one's production or comprehension, and evaluating learning after an activity is completed. Cognitive strategies are more limited to specific learning tasks and involve more direct manipulation of the learning material itself. Socioaffective strategies have to do with socialmediating activity and transacting with others [5].

Skills represent linguistic processing abilities that are relatively automatic in their use and combination (e g. word recognition, syntactic processing) [6]. Skills are automatic processes that fluent language learners use unconsciously in learning a language, while strategies are a set of abilities under conscious control when they are applied in language learning. In most educational psychology discussions of skills, they are seeing as a general learning outcomes of goaldriven tasks, acquired gradually and eventually automatised [6]. It would, of course, take lots of practice for learners to learn be a skillful learner, who can automatically employ their skills in language learning.

\section{READING SKILLS}

There exist a debate about reading skills and the components of reading skills. Shu Dingfang (2001) defined reading skills as a series of techniques and ways needed to understand and appreciate certain reading material. According to Davis (1984), there are four kinds of reading skills:1) recognizing the meaning of the words; 2) inferring; 3) recognizing the writer's writing skill, intention and style; 4) finding relevant answers[7].

Now, it is agreed that skills are all kinds of ways acquired unconsciously by readers in the process of their 
reading, like guessing a word's meaning according to its context, prefix or suffix, different readers may use different ways to solve the same problem. In contrast, strategies is certain techniques or ways used by readers to solve a particular reading task, for example, skimming and scanning now have been regarded as the two most commonly used strategies in fast reading. To make it clear, strategies are the ways or techniques we need to guide our reading, while skills are the specific techniques to help us solve different problems in the process of our reading. Their relationship is like what between teachers and students. To finish the same task, teachers give students the same guidance or technique, which may consider as strategies. However, when finishing this task, different students may meet different problems in their reading process, even though they may use the same strategy to finish this task. Take fast reading for example, students are all instructed to use the same strategy, like skimming to find the main idea of a reading passage. In fact, when doing this, different students may meet different difficulties and use different reading skills to help their skimming exercises.

In recent years, many reading materials are designed to develop readers' reading skills. Most teachers and students alike give much priority to enhance reading skills, believing that reading is an important means of language learning. As a result, fluent readers have posses some common reading skills. Teaching these learners to apply their routine skills in listening may help them find a new way to improve their listening ability and develop their own listening skills as well.

\section{THE APPLICATION OF READING SKILLS IN LISTENING}

\section{A. Distinguishing between Ideas and Details}

Generally speaking, a passage contains a general idea, several supporting ideas and their supporting details. Without doubt, the most important element in any reading passage is the main idea or general idea. Naturally, the writer would develop and explain it by giving supporting ideas and their details or specific examples. In reading, it is often suggested that reader should read for the main idea, then the supporting ideas and learn to distinguish between the sub-ideas and their supporting details. In doing so, readers can have a clear idea of the organization of the reading passage, which may not only make reading easier, but also help enhancing reading comprehension to a certain extent.

In listening, it is undoubtedly of great use for listeners to learn to recognize the main idea, sub-ideas and their supporting details or specific examples as readers do in reading comprehension. On the one hand, listeners can fully better understand the listening passage by just focus on the main idea and the supporting ideas without worrying about the details, which may not be important both for the speaker and listener as well, or which may be difficult for the listener and make listeners frustrated in the listening practice, resulting their loss of listening interest.

On the other hand, listeners can make use of the supporting details or examples, which are often stated in much easier expressions, to help their inferring the sub-ideas, or even the main idea of the listening material if they fail to catch the main idea, or supporting ideas because of their failure to distribute their attention focus properly or difficulty in understanding the sentences expressing the the main idea or supporting ideas, for example:

Many expressions may be used to describe someone who is excited. One such expression is to be "beside oneself". You can be beside yourself with anger or beside yourself with happiness, although usually not both at the same time! If you are beside yourself, you are filled with excitement.

The dictionary tells us that "beside" means "next to", or "at the side of". So the expression "beside oneself" describes something that really is not possible.

Today, you might hear a husband say, "When my wife told me we were going to have a baby, I was beside myself with joy." Or someone might tell you he was beside himself with anger because he had just lost his job.

When you are full of joy or are extremely excited about something, you may do something else that is strange. You may "flip your lid". A lid is the cover that prevents something from escaping from a container. A lid on a cooking pot, for example, keeps the heat from escaping. To flip something is to turn it over. So when you "flip your lid", you become so excited that you lose your self-control.

In this passage, the speaker develop the main idea: many expressions may be used to describe someone who is excited by giving listeners two expressions (sub-ideas): 1) 'beside oneself', 2) 'flip your lid'. Then it provides more details to show the origins of the two expressions (sub-ideas) and what conditions these expressions describe today.

Learning to apply the reading skill of distinguishing ideas and details to listening, listeners will have a clear idea of the organization of this listening passage, which will help them to finish its listening exercise. Take this question for example what condition does the expression 'besides oneself' describe today? Most students may feel it difficulty to choose the answer for this question, for they often fail to catch the first sentence, which may often express the main idea of the listening passage. Some may choose the one which is stated directly by the speaker to explain the origin of this expression, unable to make use of the two simple and easy examples(supporting details) to help them to infer the sub-idea expressed by the speaker. At this time, if students were guided by the teacher to recall the two examples in paragraph 3 given by the speaker to show the two different conditions when this expression is used. Most likely, the the answer may click in students' mind.

\section{B. Making Use of Signal Words to Enhance Listening Efficiency}

Signal words provide an aid for readers to grasp the thread of thought in the material to be read. By using signal words to predict what may come next, readers can reasonably decide their reading speed, adjust their attention focus, and summarize the main idea, thus improving their reading speed and accuracy. There are basically five groups of signal words:1) words that signal more of the same, 2) 
words that change the direction of thought, 3) words that signal an order or sequence of events, 4) words that signal a summary is about to be made, and 5)words that signal cause and effect[8].

Signal words can improve listener's listening ability by arousing their attention to help them to adjust their focus of attention target are the key meta-cognitive strategies to improve listening ability[9]. If listeners learn to decide the functions of signal words help their listening, especially those words that signal the change of thought, and those that signal an order or sequence of event. For instance:

College professors are often believed to lead easy lives of quiet thinking while teaching one or two classes every week. But actually they do much more than that. The average professor spends between six and fifteen hours in the classroom weekly, yet works from sixty to eight hours a week.

This is the first paragraph of a listening passage titled 'What College Professors Do'. The main idea, of course, is college professors lead busy lives, not easy lives that most people believe college professors do. However, some poor listeners are likely to think that the main idea is: college professors lead easy lives, because they can easily catch and deeply impressed by the two simple words 'easy lives', so much so that they fail to focus on the signal word 'but', and the following supporting details showing how busy college professions can be. Actually, most students can make a sound judgment if they are told to pay attention to the signal word 'but', which signals the change of thought direction, and learn to use supporting details to infer ideas before the listening practice. Actually, the idea introduced by signal words is what the speaker really want to convey to the listeners.

\section{Using Context Clues for Word Meanings}

When reading, readers will inevitably find some words that they don't know. But few readers will look up the new word in the dictionary, for they can often figure out meanings for new words or expressions by looking at the context of each word or expression without using the dictionary. Context refers to that which occurs before and/or after a word, a phrase or even a longer utterance or text [10]. In reading and listening as well, learners often define context as the sentence that the word or expression, which is new to them, is in and the sentences come before or after. It is usually possible to find the clues about the new word or expression from the context both in reading and listening. Readers are often taught to learn to use context clues to guess word meaning. Listeners can also make use of context hints to help their understanding even though they don't have the opportunity of regression. However, the input information of the listening material can hold long enough in listeners' short memory for them to decode, providing listeners the chances to guess the new word' meaning according to its context.

\section{1) Restatements}

Sometimes the writer knows that a word or expression is unfamiliar to many readers. To make the word or expression easier to understand, writers may include a restatement, expressing the same idea again in a different way, to make his or her idea easily understood by the reader. Learning to detect or recognize restatement in the listening material will help listeners guess some new words' meaning, thus enhancing their listening comprehension. Restatements are usually expressed in two ways: a) the restatement go directly after the new word(s), separated by a comma; b) the restatement are introduced by some words, like 'or', and 'in other words', separated by a comma, indicating that the following are restatement. The italicized words are restatements in the following examples:

- If I couldn't live in the campo, the countryside--- an unthinkable thought --- I don't know what I'd do.

- Ashley's study won the International Stockholm Junior Water Prize, a virtual Nobel Prize for teenagers

- Ashley feared that antibiotics in the waters could to resistant bacterial, or supergerms. They can kill countless people.

- Obviously we learn early that "Clothes make the man." In other words, clothes show age, outlook, status and income.

Obviously, if listeners can recognize the restatement in the first example in the sentence, they can easily guess that 'the countryside' is the contextual meaning of the new word, 'campo'. Likewise, in the second example, the restatement, 'a virtual Nobel Prize' gives listeners a clear idea of what 'the International Stockholm Junior Water Prize' is. While in the third and fourth example, the restatement are introduced by 'or' and 'in other words', which clearly indicate that explanations will be given in the following sentence.

\section{2) Parallel Constructions}

In reading, if some of the new words are parallel to other words that are familiar to readers in the context, which make it possible for them to know which class do these words fall into, readers may have a vague idea of these words' classification. Then, there is no need for them to know exactly the new words' meaning, because these new words' parallel constructions may help readers' reading comprehension if they can recognize these words are parallel with their familiar constructions. Listeners may also adopt this reading skill to minimize the difficulties in their listening process by detecting parallel constructions. The following is an interview between a police officer and a hostess talking about the stressful life of police officers.

--- I've been a police officer for thirty years.

---Thirty years! And you've had different types of assignments on the police force, I guess.

---Yeah, I've done everything from patrol to undercover work to detective work, and now I'm supervising investigations.

---Yes, it is, and the stress level not only manifests itself in daily health --- whether or not you're feeling well on any given day. It also manifests itself in things like ulcers, heart disease. 
---Police officers tend to have a higher rate of heart disease and ulcers than people in other profession.

In the interview, there are two parallel constructions. One is the introduction of what kind of jobs that the police officer has taken in the past his 30 years. Listeners who can recognize the parallel parts may infer that 'detective work, undercover work and supervising investigations,' are different types of work of police officers, for they already know the meaning of the word 'patrol 'in the Word Bank given before the listening exercises. Another is the diseases that more police officers tend to have than general people do. Listeners may infer that 'ulcers' can be a disease, because they are very familiar with the expression 'heart attack', and the two expressions are parallel to each other.

\section{3) Contrasts}

The use of a contrast can give both readers and listeners a hint to the meaning of an unfamiliar word. Most readers are good at guessing new words' meaning by recognizing contrasts in the context, which tells them the opposite of what a new word means. Listeners can be instructed to make use of the contrasts given by the writer to help their inference of new words' meaning too. Examples follow.

It's very difficult to adapt to the slower pace of the campo. In the city, you live faster and you are less attentive to nature. We've lost that in the city. We've lost some of our humanity, which my husband hasn't lost. He's not caught up in the trivia of everyday life. You can really get consumed by small things, and you forget what is important.

In this passage, the speaker is making a contrast between city life and campo life. There are two contrasts in the first two sentences: a) campo and city, b) slower and faster. By recognizing contrasts in the context, listeners can easily infer that the new word, campo, a Spanish word, means countryside.

The following is a true or false listening exercise, having two pairs of contrasts: a) happy and angry, b) smiling and frowning. Before the listening practice, listeners can be encouraged to guess the meaning of the new word 'frowning' by directing students' attention to these contrasts. If so, they may work out the meaning of the new word, frowning, which show the opposite facial expression of smiling.

- The smiling students could remember more of the happy article than the frowning students.

- The smiling students could also remember more of the angry article than the frowning students.

- According to the speaker, facial expressions might affect a person's memory.

- Nowadays the specialists understand why facial expressions can help to improve memory.

\section{4) Life Experience and General Knowledge}

In reading, readers may find it easy to guess the meaning of many new words simply by employing their own life experience or general knowledge of the subject mentioned in the reading material. In listening practice, some listeners can make an intelligent guess of the meaning of some new words or expressions by associating the new words with their own life experience or general knowledge. Just look at the following example:

A candidate who wore headphones to the interview and, when asked to remove them, explained that she could listen to the interview and the music at the same time.

On hearing this sentence, listeners will automatically relate what is described to their life experience: not wearing a headphone during an interview. So, we take off the headphones and 'remove', of course, means 'take off'.

The following is an example showing us how our general knowledge help us infer what ' intelligent' and 'school' may mean by using our general knowledge about school system and these expressions' context: a four-year old is studying at college. In the context, school should refer to kindergarten, and intelligent means clever.

Nicholas MacMahon is a four-year-old child. He is studying at college because he is too intelligent for school. Nicholas has computer lessons at the West London Institute. He spoke well before he was one year old. At eighteen months he took telephone message for parents.

\section{CONCLUSION}

It takes not only strategies but also skills to improve foreign language learners' listening ability. In addition to training students' listening strategies, teachers should also focus on the training of listening skills. Teaching students to learn to apply some of their familiar reading skills to their listening comprehension process, which are often used skillfully by them in their reading comprehension, may help them find a new way to improve their listening comprehension, and boost their confidence in listening as well.

\section{REFERENCES}

[1] Runqing Lui, Manchun Dai. 2003. Chinese College English Teaching Reform; Study on Current Situation and Development Strategies[M]. Beijing: Foreign Language Teaching and Research Press.

[2] Lifei Wang.(2000). A survey of modern second language learning and teaching. Shanghai: Shanghai Foreign Language Education Press.

[3] Larsen-Freeman, D. \& Long, M. H. (2000). An introduction to second language acquisition research. Beijing: Foreign Language Teaching and Research Press.

[4] O'Malley, J. M. \& Chamot, A.U.(2001). Learning strategies in second language acquisition.Shanghai: Shanghai Foreign Language Education Press.

[5] Brown, H.D.(2003). Principles of language Learning and teaching. Beijing: Foreign Language Teaching and Research Press.

[6] Grabe, W. \& Stiller, F.L.(2011) Teaching and researching reading. Great Britain: Pearson Education Limited.

[7] Dingfang Shu (2001). Modern Foreign Language Teaching --- Theory, Practice and Methods [M]. Shanghai: Shanghai Foreign Language Education Press.

[8] Li Yinhua, et al. College English-intensive reading(3). Shanghai: Shanghai Foreign Language Education Press.

[9] Jianding Yang 2003a. Listening Comprehension Strategy Training and Teachers' Role [J]. Foreign Language Study (3): 66-71. 
[10] Richards, J.C. \& Platt, J. et al. (2003). Longman dictionary of language teaching and applied linguistics. Beijing: Foreign Language Teaching and Research Press. 